\title{
An absolute distinction between faith and science: contrast without compartmentalization
}

\author{
Hermen Kroesbergen
}

Hermen Kroesbergen is Senior Postdoctoral Fellow for Systematic Theology at the University of Pretoria, Pretoria, South Africa; e-mail: hermen.kroesbergen@gmail.com.

\begin{abstract}
This article argues for acknowledging the existence of an absolute distinction between faith and science. It is often assumed in the science-and-religion debate that such a distinction would be a-historical and un-contextual. After discussing this critique the analogy with love and facts will be used to bring out that an absolute distinction between faith and science may exist nonetheless. This contrast, however, does not imply compartmentalization. It is shown that the absolute distinction between faith and science is of crucial importance to understand the historical contexts that so many contributors to the science-and-religion debate refer to their argument against the approaches of independence or contrast. The article concludes that within our messy and complex practices there is an absolute distinction between faith and science - our historical contexts cannot be understood without it.
\end{abstract}

\section{Key words:}

science and religion; independence; contrast; compartmentalization; taxonomies; absolute

\section{Introduction}

Can there be an absolute distinction between faith and science? John Headley Brooke and Geoffrey Cantor speak for many in the field of the religion-and-science debate when they claim that such an assumption "is thoroughly a-historical and flies in the face of the diversity displayed through the study of history" $(1998,275)$. This article shows that this outright dismissal of an absolute distinction between faith and science both misunderstands what such an absolute distinction may imply, and that such a dismissal, in fact, necessarily misrepresents the very historical contexts they refer to in their argument.

First, I will explore what is involved in the critique that it is a-historical or uncontextual to assume an absolute distinction between faith and science. Second, I will argue that absolute distinctions are necessary to understand our historical contexts, and that the absolute distinction between faith and science is one of these distinctions that is presupposed within our ordinary practices. And, third, I will discuss some of the implications of acknowledging the presence of an absolute distinction between faith and science in our historical contexts.

\section{Why is there supposed to be no absolute distinction between faith and science?}

Over the years many people have tried to classify the different ways in which religion and science relate to one another. One of the most influential and earliest to do so was the scientist and theologian lan G. Barbour, whose taxonomy is still among those most widely used. Barbour distinguishes four options: Conflict, Independence, Dialogue and Integration. 
According to the approach of Conflict, religion and science present rival pictures of the world and only one of them can be true. Integration attempts to combine the religious and the scientific worldview into a single whole, whereas Dialogue also looks for connections between religion and science, while acknowledging that they will never become fully one Dialogue preserves "the integrity of each field" (Barbour 2000, 27). The approach of Independence, lastly, is described by Barbour as follows: "science and religion are strangers who can coexist as long as they keep a safe distance from each other" $(2000,2)$, and: "In comparing science and religion, Dialogue emphasizes similarities in presuppositions, methods, and concepts, whereas Independence emphasizes differences" $(2000,23)$.

In the option of Independence science and religion are compared to two different languages: "scientific and religious assertions are two kinds of language that do not compete because they serve completely different functions in human life. They answer contrasting questions." Barbour connects this approach to Wittgenstein: "Each 'language game' (as Ludwig Wittgenstein and his followers called it) is distinguished by the way it is used in a social context. Science and religion do totally different jobs, and neither should be judged by the standards of the other" $(2000,19)$. According to Barbour's description in the Independence approach, religion and science represent two strictly segregated parts of society: "We can accept both science and religion if we keep them in separate watertight compartments of our lives. Compartmentalization avoids conflict, but at the price of preventing any constructive interaction" $(2000,2)$. For Barbour, maintaining an absolute distinction or contrast between faith and science equals compartmentalization.

As is already clear from these remarks, Barbour himself is not in favor of the Independence approach. He states: "I believe that Dialogue and Integration are more promising ways to bring scientific and religious insights together than either Conflict or Independence" $(2000,79)$. Now this is, of course, a bit tautological: Conflict and Independence do not even attempt to 'bring scientific and religious insights together', so obviously they are not the best approaches to pick if that is what you want; but Barbour and others are disqualifying the Independence approach for other reasons as well. Barbour states: "We must always keep in mind the rich diversity of our experience. We distort it if we cut it up into separate realms or watertight compartments" $(2000,37)$. He wants to do justice to the 'rich diversity of our experience' and this diversity does not allow for an approach emphasizing strict separations. Barbour admits that religion is different - it has distinct methods, questions and functions, but he argues: "We cannot remain content with science and religion as unrelated languages if they are languages about the same world" $(2000,21)$. I will return later in this article to the significant difference between Barbour's statement here that they are languages about the same world, instead of merely saying that they are languages within the same world.

Barbour is concerned about "the possibility of constructive dialogue and mutual enrichment" $(2000,21)$, that seems to ruled out by the Independence approach. Moreover, according to him, this approach does not do justice to our experience of the world: "We do not experience life as neatly divided into separate compartments; we experience it in wholeness and interconnectedness before we develop particular disciplines to study different aspects of it" $(2000,22)$. In our experience of the world everything is interconnected, in such a way that Barbour finds it hard to make sense of a strict division between faith and science, arguing like Brooke and Cantor quoted in the introduction. According to Barbour the position of Independence fails to do justice to the rich diversity of our experience of the world, the interconnectedness and interaction between different parts 
of our lives, including science and religion. It is not contextual enough. A similar judgment can be recognized in other taxonomies of the relationship between science and religion.

John F. Haught's classification in 1995 - admired by Barbour for having all categories beginning with the same letter $(2000,4)$ - listed Conflict, Contrast, Contact and Confirmation (Haught 1995, 9). In 2012 he remained with three categories: Conflict, Contrast and Convergence (Haught 2012, 13). The categories are fairly similar to those of Barbour and his critique of the option Contrast - which equals Barbour's category of Independence - is as well: "The method of contrast leaves things at a frustrating impasse. . . . in the real world [science and religion] cannot be as easily compartmentalized as the contrast position supposes" (Haught 1995, 17). Haught observes that "science and religion inevitably interact" $(1995,3)$, and asks the rhetorical question: "Isn't the contrast approach simply trying to avoid the messiness of a conversation?" $(1995,38)$. The option of Contrast or Independence is supposedly unable to do justice to the messiness of our day to day lives.

Willem B. Drees presents a more elaborate classification with nine categories, complaining that Barbour "lumps together various views of independence" (1998, 43n.). However, Drees is not much more positive about the independence option than Barbour is, arguing that "the observation that understanding is always relative to a framework does not exclude further analysis" $(1998,49)$. Elsewhere, Drees states that in order to maintain an independence model of science and religion co-existing as autonomous systems without interfering with one another, a very artificial kind of religion is required: "Co-existence requires an austere emphasis on transcendence on the side of religion" $(2015,290)$. Ted Peters $(1998,17 f$.$) and Robert John Russell (2001,269)$ in their taxonomies of sciencereligion relationships dismiss Independence in the same vein as supposedly unable to do justice to the messiness of all the interactions within our historical contexts. Finally, influential author on science and religion John Polkinghorne holds that the approach designated as Independence or Contrast is both "contrary to actual experience" and "rationally flawed": "To maintain its asserted separation it needs to appeal to highly dubious dichotomies, such as the notion that science deals only with public facts and religion only with private opinions. Both halves of this statement are in error" $(2005,45)$.

Defending an absolute distinction between faith and science is considered to be both contradictory to the facts of our historical contexts throughout the ages, and based on rationally untenable dichotomies. Before showing how this critique misunderstands both our historical contexts and what such an absolute distinction between faith and science implies, let us first look at some authors who take the critique that a sharp distinction between science and religion is a-historical and un-contextual one step further, and criticize the entire project of classifying different relationships between two presupposed entities 'religion' and 'science'.

\section{What is supposedly wrong with the whole project of taxonomies?}

Each taxonomy of the relationship between science and religion, obviously, presupposes some distinction between science and religion - otherwise all the different categories, such as conflict, dialogue and so on, would not even make sense. It can always be asked: a conflict or dialogue between what? If the critique that a sharp distinction between faith and science is untenable because it is supposedly a-historical and un-contextual is accepted, does it not follow that the entire project of taxonomies is questionable? The South African philosopher J. Wentzel Van Huyssteen seems to draw that consequence: "Both theology and science are 
cultural phenomena: as modes of theoretical reflection they may not only mean different things at different times, but - since both are located in living, developing, evolving traditions - the boundaries between them are constantly shifting" $(1998,23)$. If the two entities do not have clear boundaries, how could the relationships between them be expected to be clear? Elsewhere Van Huyssteen, therefore, concludes: "We have clearly been robbed of any general, universal, or abstract ways to talk about the relationship between religion and science today" (1998b, 23). All the different proposals to classify different ways in which science and religion can relate, are, according to him, "too generic, too universal, as categories that intend to catch the complexity of the ongoing exchange between these two dominant forces in our culture," and he concludes that "The only way in which this complex but important relationship can really be adequately approached would be by looking at how it plays out contextually" (Van Huyssteen 1998b, 3). The whole project of taxonomies of the relationship between science and religion is not contextual enough.

In a historical study on the interactions between science and religion John Hedley Brooke draws a similar conclusion: "Serious scholarship in the history of science has revealed so extraordinarily rich and complex a relationship between science and religion in the past that general theses are difficult to sustain. The real lesson turns out to be the complexity" $(1991,5)$. Drees calls this the "complexity thesis" $(2015,289)$. Olson adds that the same conclusion would follow from a study of the history of religion, concluding that "From the point of view of an historian, the taxonomies of Barbour and others are not very helpful because they do not suggest any dynamic dimension." Elsewhere Brooke and Cantor reiterate the same conclusion, adding that the approach of coming up with taxonomies represent an "essentialist position" and - as I quoted in the introduction to this article - "is thoroughly a-historical and flies in the face of the diversity displayed through the study of history" $(1998,275)$. Historical research would render is completely useless to even attempt to summarize the possible different relationships between science and religion.

Cantor, together with Chris Kenny, states:: "In contrast to Barbour's attempt to construct both science and religion as categories abstracted from historical dynamics, we suggest that the individual human life-i.e., biography-can provide a major locus for studying science-religion interactions" (2001, 779, see as well Brooke and Cantor 1998, 276). Studying concrete biographies will show that the classifications of relationships between science and religion are empty, according to Brooke, Cantor and Kenny. The reality, both historically, biographically and for every particular individual, is messier and more complex than all distinctions between science and religion allow.

In summary, the argument brought forward against an absolute distinction between faith and science, and against taxonomies of faith and science, is the same: it is supposed to be a-historical and un-contextual. But if this distinction is as a-historical and un-contextual as is argued, why have so many people used it? Barbour and most other designers of taxonomies of science and religion admit that their classifications only have a limited use. Barbour states: "To be sure, students can gain a sophisticated understanding of sciencereligion relationships through biographies of scientists, but typologies might still be useful in introductory courses if their limitations are pointed out" $(2002,347)$. The taxonomy is just a tool intended to be "helpful to readers new to this interdisciplinary field," and as such it is "necessarily selective and they may oversimplify the complexities of the real world" (Barbour $2000,5)$. The taxonomy is only intended for educational purposes, as an introduction to the field. 
In a similar vein, the theologian lan A. McFarland states: "Barbour's categories of conflict, independence, dialogue, and integration have a common-sense plausibility that make them a pedagogically useful guide to the relevant literature" $(2003,192)$. The taxonomies which presuppose some distinction between science and religion are just a ladder to allow people into the field of science-and-religion. Once they are there, this ladder is no longer necessary, and people can start to study the complex and messy historical contexts and biographies. However, this defense of taxonomies as simply a pedagogical means is misguided.

Both authors who design taxonomies of the relationship between science and religion and authors who are critical of the whole project of designing taxonomies oppose an absolute distinction between faith and science. I, on the other hand, would like to argue for the importance of this distinction even far beyond such an pedagogical use, but before I will come to the core of my own argument, one more thing needs to be clarified about the argument that a distinction between science and religion is supposed to be a-historical and un-contextual. 'Science' and 'religion' as such are supposed not to exist. But what are these apparently non-existent categories considered to represent?

\section{An absolute distinction between what?}

As quoted above Wentzel Van Huyssteen speaks of theology and science as 'cultural phenomena', 'modes of theoretical reflection', and 'dominant forces in our culture.' In the introduction to the Encyclopedia on Science and Religion he writes: "This relationship involves two of the dominant cultural forces of our time," again arguing for a more contextual and historical approach: "Complicated and multi-layered, the relationships among the various sciences and diverse world religions are not merely adversarial, nor simply a matter of neatly separable domains of discourse" (Van Huyssteen 2003, x). In order to be able to discuss the argument that an absolute distinction between faith and science is a-historical and un-contextual it needs to be clear what faith and science are supposed to be.

The phrases 'forces in our culture' and 'cultural forces in our time' indicate that science and religion could be identified if our surroundings are looked at from a anthropological or journalistic point of view, describing what is going on, on a par with the music scene or labor unions. Science and religion can then be considered as "interacting subcultures," as Richard Olson $(2011,65)$ proposes. The phrase "mode of theoretical reflection', on the other hand, could suggest a more internal or conceptual perspective, with science and religion on a par with visual observation or material culture. Science and religion would then not represent two cultures or subcultures, but two aspects of reality that are considered within a culture or subculture.

Barbour combines these two perspectives by referring to science and religion as "two fields" or "area[s] of life and thought" which can be distinguished "according to the questions they ask, the domains to which they refer, and the methods they employ" (2000, 17). The emphasis here is on science and religion as two parts of society or subcultures, and the conceptual perspective is only used to distinguish these two segments of what is going on in the world. Science and religion are considered more as parts of society than as aspects of reality.

A similar approach can be found in one of the most vocal defenders of the Independence or Contrast option, Stephen Jay Gould. He speaks about two "nonoverlapping magisteria" $(2014,7)$ derived from the word magisterium as referring to the teaching 
authority of the (Roman Catholic) church. Religion and science both tell us about a particular part of the world. They have a division of labor, which implies that, instead of being the designations of labor, science and religion are doing labor, their own kind of labor that is. Science and religion are considered to be subcultures rather than activities within culture (see also Olson 2011, 80).

As Richard H. Bube, another representative of the Independence or Contrast option, states: "Science and theology tell us different kind of things about the same things." (1995, 34). Science and religion are supposed to tell us things. These defenders of the Independence or Contrast option as well as their critics ascribe activities to science and religion- there is or is not a division of labor, they are forces in culture, or sub-cultures they are considered to be two parts of society or subcultures, with both their own questions and methods to identify them.

An independence or contrast between science and religion as two independent or separate parts of society is the perspective that is criticized by the opponents of the independence approach as well. As Barbour remarks: "Independence ... also can be termed Separation or Compartmentalization" $(2008,266)$, and "Science and religion do totally different jobs" $(2000,19)$ : that is, there are two compartments of society engaged in two different activities.

In what follows I want to argue for a different kind of Independence or Contrast: Contrast without Compartmentalization, for an absolute distinction between faith and science does not need to refer to two parts of society, it can also be a contrast within one and the same society, it can refer to two aspects of reality which are dealt with in different ways within society.

\section{An absolute distinction between absolute concepts}

In the complex, messy, historical contexts of our society there is not a clear clash between two parts of society that can be named 'science' and 'religion' - there are no clear battlefields and frontlines as there may be in a students' protest or mine workers' strike. However, of course, in the complex, messy, historical contexts of our society there is a distinction or even many distinctions between 'science' and 'religion' as aspects of reality this is almost tautological: two different terms are used. The historical context would not be understandable for someone who does not see a distinction between what people call 'science' and what people call 'religion'. In fact, it would show a lack of understanding if a researcher could not predict with reasonable accuracy what his or her informants would call 'science' and what they would call 'religion'.

The complexity that Brooke cum suis see in our historical contexts with respect to science and religion would not even be a complexity if science and religion were not distinguished. The wild and messy diversity that these authors draw are attention to, would not be wild and messy and diverse, if there was no difference between science and religion. A messy painting of green and red strokes would not be messy for colorblind person who sees no difference between green and red. What is considered to be the historical contexts in the science-and-religion debate is logically parasitical upon a distinction between science and religion. On the one hand, this is a platitude, such as the platitude that even someone who says that there is no distinction between religion and science, is already presupposing a distinction by speaking of 'religion' and 'science', on the other hand, what I would like to 
argue here goes beyond that, in stating that the distinction between religion and science that is found in our historical contexts is an absolute distinction.

Every context presupposes what I would like to call absolute concepts. These concepts refer to things that do not exist at any particular time or place, but as concepts they are present within the context. As such these concepts can be seen as a sub-category of abstract concepts, like types of things or ideas, in contrast to concrete concepts which refer to particular specific things. Absolute concepts derive their meaning not from what is found in our contexts, but from how people look at what is found in our contexts, and from their relationship to other absolute concepts. I will argue that faith and science are absolute concepts that stand in a relationship of absolute distinction from one another, like light and darkness. Dark is the opposite of light, not because this happens to be so in our historical contexts, but because that is how we define 'dark'. In our historical contexts neither absolute darkness nor absolute light may exist, but we use this absolute contrast to identify some place in our context as dark and another as light.

Not all abstract concepts fall into the category of what I call here absolute concepts. Scientists may speculate about 'black holes' as pure darkness, so some idea of what pure darkness might be exists, although it will probably never be encountered in our day to day lives. We have no idea what it would be like to encounter the abstract concept 'five' or 'redness', but about the absolute concepts we do have some idea of what they would look like - although we might be pretty sure that we will never come across them. The absolute concepts represent ideals or perfections which can be imagined to strive for, in a way that it is not imaginable to strive for 'five' or 'redness.' In some Platonic conceptions this distinction is obscured because there all abstracts are patterned upon properly ideal concepts such as goodness or beauty. Whether the ideals represented by absolute concepts do exist in a real way as in some Platonic conceptions, or not exist in a real way as in nominalist positions, does not matter for my argument. In both cases the absolute concepts do not refer to something we may stumble upon in our day to day practices, but they do guide and define how we view those practices: what we call religious, what we call beautiful, etc.

The absolute concepts are absolute in the sense that they are both abstract and ideal, and in the role they play in ordinary language. How we speak about concrete things in our contexts derives its meaning from these absolutes. What we say in connection with specific concrete manifestations of religion derives its meaning from and is related to our absolute concept of religion. Green grass is really green, five bottles are really five bottles, but to say of something that it is religious is never true in the same sense. Pure religion is never encountered in that way, but it is present as an ideal, something to strive for. Our judgments in this respect are always relative, derived from the absolute concepts we use to make these judgments. However messy the historical context may be the absolute concept retains its purity by definition, since it is definition of what in particular contexts is meant by, for example, religion.

Absolute concepts relate to our concrete and relative judgments, but they do also relate to one another in different ways. Absolute concepts are distinct from one another: love is not religion, but love can be a part of religion. Absolute concepts can also stand in absolute contrast to one another. I want to argue in the rest of this article that between faith and science there exists such an absolute distinction: as concepts that are used in our messy historical contexts, where they may never be found in a pure form, yet they are defined over against each other. If something is part of faith it is not part of science, if it is part of science it is not part of faith. In this way the distinction between these two absolute concepts is itself 
absolute. Whether such an absolute distinction exists between the absolute concepts of faith and science, is something I will return to later.

It is a platitude that faith and science are distinct concepts and, therefore, as such distinguishable from one another. This in itself is important enough, and deserves to be acknowledged more thoroughly in discussions on science and religion. However, what I want to argue here is that they are defined in contrast to each other, which makes this conceptual distinction even more important: it explains what Olson calls the "well-established historical master narrative" of conflict and warfare between science and religion $(2011,69)$. Olson states that "psychosocial considerations make it virtually impossible to undermine simply by piling up counterexamples and claiming that things are complex" $(2011,68 f$.$) , but I would$ argue that the conceptual confusion might be an even more important explanation than psychosocial considerations for the pervasiveness of the conflict-framework. Moreover, the absolute, conceptual distinction between faith and science has yet more radical implications to which I will turn near the end of this article.

If we want to do justice to the very messy historical contexts that the critics of an absolute distinction between faith and science are referring to, we need to pay attention to how in these contexts there is an absolute distinction between the concepts of faith and science. As the primary argument against an absolute distinction between science and religion, the critics cited above emphasize the messiness of our historical contexts, but this only works as an argument against an absolute distinction between science and religion as parts of society, and not against a distinction between science and religion as contrasting concepts within one and the same society. In fact, those complex historical contexts that the critics refer to, presuppose an absolute distinction between science and religion as aspects of reality. Science and religion may not be separate compartments of society, but they are opposite concepts as they are used within our society. This aspect of the relationship between faith and science, which I will further elaborate in the rest of this article, needs to be acknowledged in discussions on faith and science.

\section{The analogy of love and facts}

What is meant by an absolute distinction between faith and science as concepts, and what the consequences of such a distinction are can be shown by an analogy introduced by the theologian Ian McFarland. McFarland proposes a different way of classifying the relationships between science and religion. According to him, the two main categories should be compatibility, where science and religion do not overlap, and integration, where science and religion are comparable, taking part in the same project (McFarland 2003, 182). This different approach to the taxonomy has its value, but for our topic at hand it is only relevant to see that 'type 1' of his first category "corresponds roughly to Barbour's category of independence" (McFarland 2003, 185). McFarland dismisses options that are similar to the Independence or Contrast approach in the same way as the authors discussed above. He argues against claims that properly theological claims simply do not overlap with scientific ones, since they would "fail accurately to reflect Christian practice" (McFarland 2003, 188). The criterion that McFarland uses here is the same as the authors above in that he refers to the messy, historical contexts in which distinctions between science and religion are made. He states: "The primary criterion will be empirical: How well does each of these ways of conceiving religious language correspond to the practices of believers on the ground?" (McFarland 2003, 188). An absolute distinction or contrast between faith and science is 
discarded because it would be a-historical and un-contextual if ordinary practice is taken into account.

McFarland criticizes, for example, the Wittgensteinian philosopher of religion D.Z. Phillips on these grounds: "He does not seem to leave any room for the kind of hook-up with other forms of speaking that might allow one to critique of particular instances of Christian speech as wrong (as opposed to infelicitous or confused). Again, such a position just does not seem to cohere with the Christian practice of debating what constitutes right belief" (2003, 188f.). The failure of independence approaches which see "theological and scientific language as related in a fixed and clearly describable manner", according to McFarland, is to do justice to the fact that "Christians are just not that rigorous in delimiting their religious utterances from other ways of talking. They simply do not exhibit the kind of principled objection to treating doctrinal statements as (among other things) descriptions of objective states of affairs that [Phillips] demands" $(2003,189)$. In everyday practice people are not so rigorous in their use of concepts as an absolute distinction between faith and science suggests. In a footnote he adds: "This is not to deny that there may be improper use of nontheological criteria in assessing Christian doctrines, or that individual believers may mistake the character of a faith claim; it is only to point out that such judgments must be made on a case-by-case basis" (McFarland 2003, 189n.). If the relationship between faith and science is investigated on a case-to-case basis, one will find, according to McFarland, a "rather more complicated relationship between religious and scientific statements suggested by the practice of believers on the ground" $(2003,193)$. The approaches of compatibility or independence "are unpersuasive because their construal of the relationship between religious and scientific language is too inflexible in the face of the concrete reality of religious practice" (McFarland 2003, 194). In real life contrasts such as the one between faith and science are always very flexible and complex.

So far, McFarland is rephrasing the same arguments quoted above: within the concrete reality of religious practice, especially if one considers it case by case, one does not find a sharp distinction between science and religion. It is not how actual people learn about faith and science, and not how they experience it in their ordinary lives. However, an analogy that McFarland himself introduces near the end of his article, shows that this argument is not as straightforward as it may appear. One cannot understand the concrete reality of religious practice, nor the specific cases of people's lives, if one does not acknowledge the presence within those messy, historical contexts of an absolute distinction between faith and science. Having just dismissed options which recognize an absolute distinction between faith and science as "unsatisfactory because they refused to acknowledge that scientific knowledge might contribute in any way to the evaluation of doctrinal truth or adequacy" (McFarland 2003, 196), McFarland uses an analogy to argue against what is portrayed as the other extreme, complete integration of faith and science. I will quote it at length, because I want to use the same analogy to show that an absolute distinction between faith and science is part of our day to day historical contexts.

Near the end of his article McFarland writes:

An analogy might be drawn here between the way in which facts relate to love. True as it may be that the heart has its reasons that reason does not know, it remains the case that a love that is stubbornly blind with respect to such facts as the indifference, violence, or faithlessness of the beloved has gone tragically awry. Facts make a difference - but the difference they make is a very specific one. However significant on other grounds it may be that two lovers may be of more or less the same age or social class, have the same interests, or (most basically) happen to find themselves in close geographic 
proximity, no such facts can serve to explain or justify love. It is certainly the case that some facts (e.g., the discovery by one partner that the other has profoundly misrepresented herself) have the potential to render love untenable. Such potential 'defeaters' must be taken into account in evaluating one's relationship with the beloved. But no set of facts finally justifies love. In the last analysis love cannot be explained or justified in terms other than its own, and neither can faith $(2003,197)$.

McFarland compares the relationship between faith and science here to the relationship between love and facts. In all kind of ways facts play a role within love: facts are important for lovers to find one another, facts come into play during a love relationship, and facts could be 'defeaters' causing love to end. However, McFarland argues that in the final or last analysis love cannot be explained or justified in terms of facts, the facts that play a role in love do play the role they play because they have been taken up within the terms of love within the context of love it is defined which facts play a role and in what way.

For McFarland this analogy illustrates how faith and science can never be completely integrated - in last analysis each remains with its own criteria for explanation and justification. According to McFarland the analogy shows that "scientific facts affecting theological reflection on a purely ad hoc basis as potential defeaters of doctrines that must be dealt with as they arise, but which play no programmatic role in the formulation or elaboration of Christian belief" $(2003,197)$. If scientific facts play a role in theological reflection it is because the scientific facts have ad hoc received a meaning within theological reflection. The justification of the importance of these scientific facts within Christian faith remains a theological matter, that can only be explained in theological terms and according to theological criteria - just like it is the case with facts and love.

I agree with McFarland's interpretation. However, he does not draw all the important conclusions that can be drawn from this analogy. Faith and science, and the relationship between the two, can be like love and facts, and the relationship between those two. In reality you may never find completely genuine love or pure facts, but in that same reality love and facts are used in concepts that stand in an absolute contrast to each other. In last analysis love cannot be explained or justified in terms other than its own, as McFarland says, a fact can count as a defeater in love but only because within love this fact is ascribed that particular role and importance. Like Jesus did not contribute to the dialogue between agriculture and faith when he used farming images in his parables, likewise someone who is inspired by science, or rather: by the Holy Spirit through scientific images, is not contributing to something like a dialogue between faith and science. A dialogue between faith and science is not possible, like a dialogue between love and facts is not possible, since there is an absolute distinction between the two - they exclude each other by definition. You can love particular facts to be true, love may influence the way you see particular facts, but as facts they are what they are with or without that love. In our historical context there is a rich diversity of love and facts, they are always interconnected in messy and diverse ways. If one pays attention to the specific contexts on the ground, one will always find a rich interactive complexity. However, this does not mean that there is not an absolute distinction between love and facts, in fact, our historical contexts are considered to be messy in this respect, because what is happening in them is compared with the absolute contrast between our concepts of love and facts. 


\section{Contrast without compartmentalization}

If something is a fact, then as such it cannot be part of love; if something is part of love, then as such it cannot be a fact. The Italian philosopher Giorgio Agamben explains how this works comparing two statements about loving Mary: 'I love beautiful-brunette-tender Mary,' not 'I love Mary because she is beautiful, brunette, tender,' in the sense of her possessing such and such an attribute. The moment when I realize that my beloved has such-and-such a quality, or such-and-such a defect, then I have irrevocably stepped out of love" $(2005,128)$. This point may be even clearer if one imagines Mary to be rich and asks with Sören Kierkegaard: "If a man loves a girl for the sake of her money, who will call him a lover? He does not love the girl, but the money. He is not a lover but a money-seeker" $(2011,73)$. As we in our contexts are using the concept of love, that is not true love. We could start to use the concept of love differently - it is our language - but as we are using it now, that is not a correct use of the concept of love. Likewise Agamben argues that Mary may be beautiful and brunette and tender, but if one says that that is why he loves Mary, we - as we are using the concept of love - would no longer call that love - or at least no longer loving Mary. That is not how we now use the concept 'love'. Within our contexts, once you start to look at facts at least at facts as facts, then you are no longer in the realm of love. Although, as Agamben admits, we may feel differently, continuing: "even if, as is often the case, I continue to believe that I love her, especially after having given good reason for continuing to do so. Love has no reason" $(2005,128)$. Love and facts exclude one another. If something is based on a fact, we would not call it love; if something seen with the eyes of love, we would not call it a fact. Despite the fact that in our historical contexts love and facts are always mixed in complex and messy ways, within these same historical contexts as concepts love and facts are defined as excluding each other.

Someone may question this conception of love as standing in absolute distinction to facts. Someone may call this conception naïve or romantic, or say that this conception of love is an illusion. To say that love is an illusion may mean different things. First, one could say that this kind of love is an illusion simply to express that you will never - or at least hardly ever - encounter this kind of love in reality. This is not an objection to the point that is being made here. Above it was already conceded that absolute concepts, such as love in this case, do not refer to things that may be found in our day to day lives. They are absolutes. As absolutes they govern what we in our contexts call an expression of love, even though in its pure form one may never encounter it. Nonetheless, it is what we strive for and it is what determines the meaning of what we say in connection with love.

Second, 'this kind of love is an illusion' may be a cynical remark, a way to disavow the contexts that Agamben, Kierkegaard and I are describing here. One may seek to claim that he is not part of these contexts, but that in his contexts love is simply a matter of give-andtake, for example. This disavowal, however, is not as easy and straightforward as it may seem. In stating that this kind of love is an illusion someone is already acknowledging the sense of this concept of love - otherwise one could not deny it. If give-and-take is someone's conception of love, it will be hard for this person to make a distinction between love and prostitution. Or even to understand what others mean by that distinction. Elsewhere I made a similar point about someone claiming that De Montaigne's concept of genuine friendship is an illusion, arguing that "it will be very hard to follow even the most shallow Hollywoodmovies. De Montaigne sees the concept of friendship he describes, as admirable, someone else may see it as foolish, but still both conform to the same conceptual structure. It is very hard to imagine someone who does not do so" (Kroesbergen 2015, 108). In reality we may 
never encounter genuine friendship, or the kind of love Agamben and Kierkegaard describe, but it is this kind of love that explains how we happen to use the words friendship and love. Even someone who says that this love is an illusion, thereby and in his or her grasp of popular culture, shows he or she shares the absolute concept of love described here.

In our messy historical contexts facts and love may always be mixed in many complicated ways, conceptually they stand in absolute opposition to one another in those very same messy historical contexts. Facts may be taken up in love in many complicated and diverse ways, but then, conceptually, they are no longer facts. As I explained in connection with friendship and gifts: "Friends give each other presents. However, these presents have their meaning within the friendship. A watch is not just a watch, it is a token of someone's friendship. This gift is internally related to the friendship, it would not be the same without or outside of the friendship" (Kroesbergen 2015, 114). Mary, in the example of Agamben, may be in fact beautiful and brunette and tender, that does not exclude the possibility of someone loving her, but he would then love 'beautiful-brunette-tender Mary' - the facts are taken up in the love and do no longer exist as separate facts outside of it, like in the case of 'I love Mary because she is beautiful, brunette, and tender.' Facts may count as justification or defeater within love, but then they are no longer facts, but derive their status from the terms of love, as McFarland phrases it. This is what an absolute distinction between concepts may look like, and I would like to argue that this is what the distinction between faith and science looks like.

The language of love and the language of facts are not so much two languages about the same world, as if the Mary who happens to be beautiful, brunette and tender is literally the same as the loved beautiful-brunette-tender Mary - as if the only difference would be using different words, as if the watch as a token of friendship is the same as a similar watch in a shop. If you do not love Mary, Mary will be in your world just as well, but, nonetheless, she will not be the same as she is for her lover. Instead of saying that love and facts are two languages about the same world, it would make more sense to say that the language of love and the language of facts are two languages within the same world. Likewise, instead of saying that faith and science "are languages about the same world," as Barbour does (2000, 21 ), it would be more accurate to say that the language of faith and the language of science are two distinct languages within the same world.

The language of love and the language of facts are not compartments of society. They are not two fields, not two forces in culture or two magisteria or teaching authorities. Love and facts are not to subcultures on a par with the music scene or labor unions. Love and facts presuppose a more internal or conceptual perspective, they are more on a par with visual observation or material culture, as relating to two aspects of reality. Likewise, faith and science are not two compartments of society, they are not two subcultures, but, nonetheless, there is a sharp contrast between them. There is an absolute distinction between the two, despite the fact that there is no compartmentalization.

Part of the definition of love is that it is not factual, part of the definition of facts is that it is not colored by love. Likewise part of the definition of science is that it is not faith, within science as science it is irrelevant what someone believes - even if in everyday practice the beliefs of scientists may play quite an important role. Religious revelation is no argument in science, one needs to prove one's statements according to scientific standards. A scientist should bracket his faith - that is, in our current contexts, part of the grammar of what it means to be a scientist. Within science faith can play no other role than that of a temptation, a pollution of genuine science. Likewise if through scientific experiments someone would 
prove that praying to Mami Wata makes you rich, that does not make you a believer. To think that it did would be a misunderstanding of the concepts of both faith and science. As Peter Winch says about the belief in the resurrection of Jesus Christ: "What would damage the integrity of such a belief is not so much a demonstration of its historical falsity as the asking of such technical historical questions in the first place. It is a belief of a sort which precludes the asking of such questions" (quoted in Springsted 2004, 368). Like although love implies giving and receiving, what would damage love is not so much to find out that you give more than you receive, but your love would already be damaged when you start making such calculation. Likewise faith excludes looking at scientific facts, and science excludes putting value in what one believes. That is part of the concepts of faith and science. If it is part of science it is not part of faith, if it is part of faith it is not part of science; this is what we happen to call science, this is what we happen to call faith; this is part of the concepts of science and faith in our contexts. Even if in practice we will never find pure examples of either faith or science.

If in our historical contexts we never encounter pure faith or pure science, if they are always interacting in messy and complex ways, as the authors quoted in the first half of this article quite rightly observed, then how is such an absolute distinction present in these historical contexts? I argued already that love and facts are present in our historical contexts as absolutes despite the fact that it will be hard to find them in a pure form, yet let us now turn to a different example, the practice of grading or marking. Imagine you see someone receiving a mark of 73 . To understand what that means, you need to know the scale on which they are marking: are they marking from 1 to 100, or from 1 to 80, or from 1 to 250? That would make a big difference in understanding the meaning of the mark that someone is getting. Maybe in practice nobody ever receives a 1, maybe nobody ever receives a 100, but to understand what a 73 means, we need to know that in this context people are marked from 1 to 100. Even if in reality the mark 100 is never given, this practice could not be properly understood without knowing that 100 is the top mark or the absolute.

Despite the fact that faith free from science may be artificial, and a dichotomous concept that one will never encounter in our messy historical contexts, this absolute conception is what gives talk about faith within our contexts its meaning, like 100 as absolute gives meaning to the mark 73 . To tell people about the absolutes governing a particular practice may help to introduce people to a field new to them. It may help to tell a new teacher that this school uses a marking system from 1 to 100, but these absolutes far exceed such a pedagogical use, since even if nobody ever needs to explicitly mention them again, the practice continues to derive its meaning from these absolutes.

Even if we do not have the school manual, studying a practice of grading or marking long enough we may discover that 100 is probably the absolute. Studying the practice on a case-to-case basis, as McFarland proposes for the study of faith and science, or studying the practice through individual biographies, as Brooke and Cantor suggest for faith and science, however, will never yield the absolutes that give meaning to the practice. To discover the absolute concepts that determine the meaning of a particular practice, we need to study not on a case-to-case basis but widely, in the practice of marking as well as in the relationship between faith and science. Not an individual case, but the continued practice shows the absolute concepts that govern such a practice. In this way the concepts of faith and science in an absolute contrast govern our practices with faith and science. Even if we never encounter pure faith or pure science in our messy historical contexts, nonetheless, within these contexts an absolute distinction between the two is shown, which is learned either 
theoretically from a textbook, but more often gradually through participating in these contexts.

\section{Conclusion}

Brooke and Cantor argued that it is completely a-historical and un-contextual to assume that there is an absolute distinction between faith and science. This opinion is widely shared among those involved in the science-and-religion debate. In this article the analogy with love and facts was used to bring out that an absolute distinction between faith and science may exist nonetheless, and even be of crucial importance to understand the historical contexts that so many contributors to the science-and-religion debate refer to in their argument. Brooke and Cantor are right that it is thoroughly a-historical and un-contextual to expect to find an absolute distinction between faith and science in our messy and complex everyday practices. However, within those same practices an absolute distinction between faith and science happens to be used, and it is vital for being able to understand these very same messy historical contexts to be aware of this sharp contrast and to reflect upon it, such as is done in this article. There can be an absolute distinction between faith and science, in fact, in our practices there is such a contrast, yet it is a contrast without compartmentalization.

\section{References}

Agamben, Giorgio. 2005. The Time That Remains: A Commentary on the Letter to the Romans. Stanford: Stanford University Press.

Barbour, Ian G. 2000. When science meets religion: Enemies, strangers, or partners?. San Francisco: Harper.

- - . 2002. "On typologies for relating science and religion." Zygon: Journal of Religion and Science 37(2): 345-360.

- - . 2008. "Taking science seriously without scientism: A response to Taede Smedes." Zygon: Journal of Religion and Science 43(1): 259-269.

Brooke, John Hedley. 1991. Science and religion: Some historical perspectives. Cambridge: Cambridge University Press.

Brooke, John Hedley, and Geoffrey N. Cantor. 1998. Reconstructing nature: The engagement of science and religion. No. 158. Oxford: Oxford University Press on Demand.

Bube, Richard H. 1995. Putting it all together: seven patterns for relating science and the Christian faith. Lanham: University Press of America.

Cantor, Geoffrey N., and Chris Kenny. 2001. "Barbour's Fourfold Way: Problems with His Taxonomy of Science-religion Relationships." Zygon: Journal of Religion and Science 36(4): 765-781.

Drees, Willem B. 1998. Religion, science and naturalism. No. 171. Cambridge: Cambridge University Press.

- - . 2015. 'Disenchantment or Conflict? Egil Asprem and 'Science and Religion' Discourses". Journal of Religion in Europe 8(3-4): 288-297.

Gould, Stephen Jay. [1997] 2014. "Nonoverlapping magisteria." Filozoficzne Aspekty Genezy 11: 7-21.

Haught, John F. 1995. Science and religion: From conflict to conversation. Mahwah: Paulist Press.

- - . 2012. Science and Faith: A New Introduction. Mahwah: Paulist Press. 
Kierkegaard, Sören. [1956] 2011. Purity of Heart: Is To Will One Thing. New York: Harper \& Row.

Kroesbergen, Hermen. 2015. "Superstition' as a contemplative term: a Wittgensteinian perspective." International Journal for Philosophy of Religion 77(2): 105-122.

McFarland, Ian A. 2003. "Conflict and compatibility: Some thoughts on the relationship between science and religion." Modern Theology 19(2): 181-202.

Olson, Richard. 2011. "A dynamic model for 'science and religion': Interacting subcultures." Zygon: Journal of Religion and Science 46(1): 65-83.

Peters, Ted (ed.). 1998. Science and theology: the new consonance. Boulder: Westview Press.

Polkinghorne, John. 2005. "The continuing interaction of science and religion." Zygon: Journal of Religion and Science 40(1): 43-49.

Russell, Robert John. 2001. "The relevance of Tillich for the theology and science dialogue." Zygon: Journal of Religion and Science 36(2): 269-308.

Springsted, Eric O. 2004. "Faith, belief and perspective: Peter Winch's philosophy of religion." Philosophical Investigations 27(4): 345-369.

Van Huyssteen, J. Wentzel. 1998. "A Contextual Coherence Theory for Rethinking Theology and Science." in Rethinking Theology and Science: Six Models for the Current Dialogue. Gregersen, Niels Henrik, and J. Wentzel Van Huyssteen, 10-50. Grand Rapids: William B. Eerdmans Publishing.

- - . 1998b. Duet or Duel?: Theology and Science in a Postmodern World. John Albert Hall Lectures. London: SCM Press.

- - - 2003. "Introduction." in Encyclopedia of Science and Religion, edited by J. Wentzel Van Huyssteen, i-xi. New York: Macmillan Reference. 